\title{
IODP Workshop on Using Ocean Drilling to Unlock the Secrets of Slow Slip Events
}

\author{
by Laura M. Wallace, Eli A. Silver, Nathan Bangs, Rebecca Bell, \\ Joshu Mountjoy, Stuart Henrys, and Ingo Pecher
}

\section{Introduction}

Subduction margins produce the largest and most destructive earthquakes and tsunami on Earth. Knowledge of the mechanics of fault slip behavior on subduction thrust interfaces is necessary to understand and mitigate the hazards posed by these major plate boundary features. The observation of episodic slow slip events (SSEs) occurring at many subduction zones worldwide (Fig. 1) is arguably one of the most exciting discoveries in the Earth sciences in the last decade. SSEs involve transient, aseismic slip on a fault, lasting days to months, at a rate intermediate between steady plate boundary displacement rate and seismic slip. Prior to the discovery of slow slip, most studies of fault behavior assumed that slip on faults occurs either as steady creep or suddenly in an earthquake. Geodetic and seismological detection of slow slip and its associated slow seismic phenomena (such as non-volcanic tremor, low-frequency and very-low frequency earthquakes) has transformed our understanding of the spectrum of fault slip behavior (Ide et al., 2007) and has fundamental implications for deformation mechanisms and rheology on subduction megathrusts.
Despite the fact that there is now abundant evidence for SSEs at many of the Earth's subduction zones, the physical mechanisms leading to slow slip behavior and the relationship of SSEs to destructive seismic slip on subduction thrusts remain unknown.

A variety of theories regarding the origin of SSEs have been proposed; many consider episodic slow slip as a consequence of high fluid pressures within a conditionally stable frictional regime. These proposed mechanisms for episodic SSE behavior arise largely from theoretical and modeling studies (Liu and Rice, 2005, 2007; Shibazaki and Iio, 2003) and interpretations of physical properties from seismic attributes (Audet et al., 2009; Bell et al., 2010; Kodaira et al., 2004; Song et al., 2009). In many ways, our understanding of the origins of slow slip events has been hampered by the fact that many of the best-studied SSEs worldwide (e.g., Cascadia, Nankai) occur at depths of 30-40 km below the Earth's surface (Dragert et al., 2001; Obara et al., 2004), and scientists must rely on indirect evidence to investigate these fascinating phenomena. However, the discovery of shallow SSEs (at $<10 \mathrm{~km}$ depth) at subduction margins in New Zealand, central Japan and Costa Rica (Douglas et al., 2005; Outerbridge et al., 2010 Ozawa et al., 2007; Sagiya, 2004; Wallace and Beavan, 2010) highlights the exciting potential for IODP drilling to gain direct access to the SSE source area, and thus to play a key role in unlocking the secrets of SSEs.

\section{Workshop Goals and Overview}

To discuss and develop a plan to use scientific ocean drilling to help advance the emerging and highly topical field of slow slip events, Integrated Ocean Drilling Program (IODP) sponsored a workshop in Gisborne, New Zealand on 1-3 August 2011. The workshop attracted seventy geoscientists from a 
dozen countries around the world and was also sponsored by the Consortium for Ocean Leadership, the New Zealand Ministry of Science and Innovation, and the U.S. National Science Foundation's (NSF's) GeoPrisms program. Gisborne was chosen as a venue due to its proximity to the source area of shallow slow slip $(<5-15 \mathrm{~km}$ depth) that occurs at the northern Hikurangi subduction margin in New Zealand. The main three-day workshop

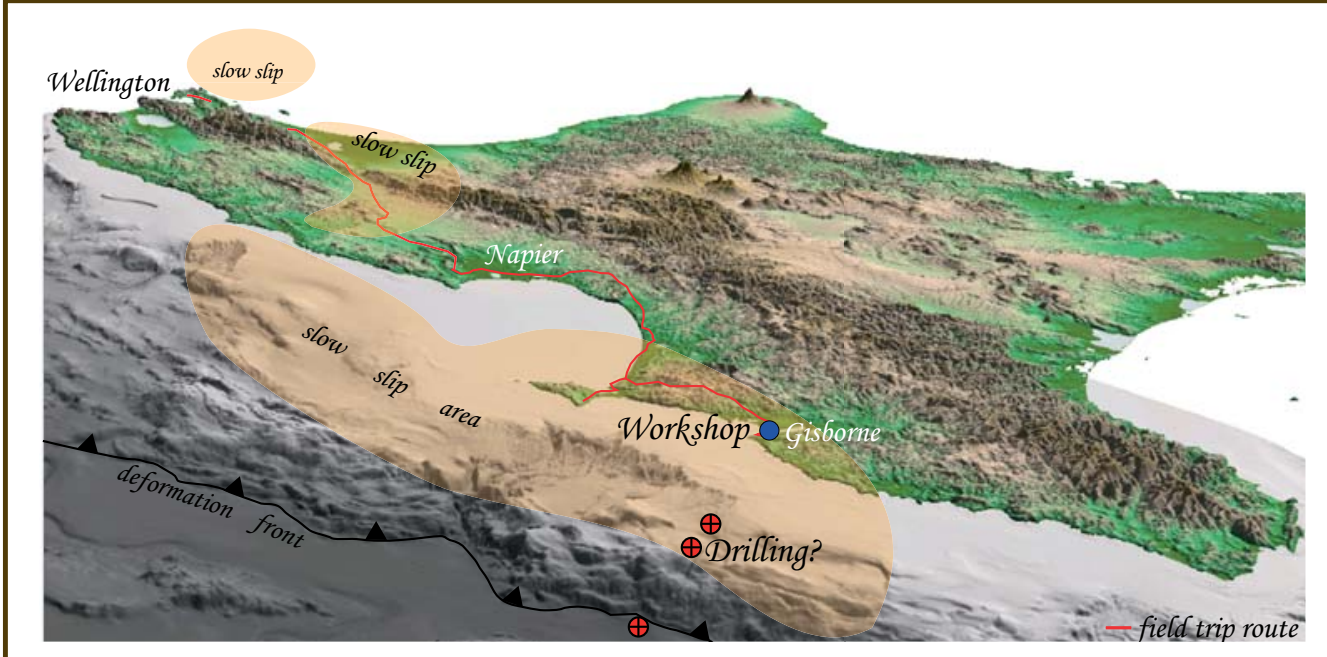

Figure 2. Oblique view of the Hikurangi subduction margin, including locations of slow slip (orange shaded areas), the location of the workshop and field trip route (orange solid line), and some of the proposed slow slip event drilling targets offshore Gisborne. was followed by a two-day

field trip (sponsored by the New Zealand Ministry of Science and Innovation) from Gisborne to Wellington (Fig. 2), designed to expose participants to the onshore, uplifted components of the Hikurangi forearc and to give participants insights into the geological and tectonic context of slow slip in New Zealand.

The primary goals of the workshop were to summarize critical requirements of a drilling program to discern the physical mechanisms responsible for SSE behavior, to develop strategies to achieve the scientific goals, to determine what types of data are needed to develop an effective drilling program, and to identify the expertise and technologies needed for drilling a SSE source area successfully. Oral presentations at the workshop centered around thematic sessions, including (1) observations of and theories for SSE occurrence, (2) lessons learned from previous IODP subduction zone drilling, and (3) potential slow slip drilling targets in New Zealand, Costa Rica, and central Japan. The talks were interspersed each day with breakout discussion sessions and broader group discussions. On the final day, breakout groups developed implementation plans for each location.

\section{Recommendations and Outcomes of the Workshop}

Overall, the workshop participants agreed that slow slip events offer a number of compelling scientific questions that can be realistically addressed by IODP drilling. Some of these questions are listed as follows. (1) What does a slow slip zone look like? Is the slip localized to one or two sharp, thin discontinuities, or is slip distributed continuously throughout a zone of finite thickness? (2) Do slow slip events occur in rocks consistent with a conditionally stable frictional regime, as suggested by theoretical studies? (3) Are slow slip events associated with low effective stress due to high pore fluid pressure? (4) Can a single fault patch host both SSEs and "normal" earthquakes? (5) Are SSEs restricted to a specific pressure or temperature range and can they propagate all the way to the trench? Participants concluded that these fundamental questions can be addressed by a strategy that includes conducting geophysical experiments, monitoring shallow instrumented bore holes above SSE source regions, logging and coring of the region above the SSE source and incoming sedimentary section, and, ultimately, by direct sampling and monitoring of the slow slip patch by deep riser drilling. During the workshop the participants discussed generic methodologies to address these questions and developed plans which could be implemented in specific locations around the world.

Auxiliary studies (e.g., non-drilling) are required for any successful SSE drilling program, and these were a major topic of discussion. In summary, participants recommended a broad range of studies with particular emphasis on collocated, integrated studies using geological and geophysical techniques that are designed and constrained with laboratory and numerical modeling. Of particular importance to determining the spatial distribution of SSEs and related seismicity are onshore geodetic and seismic experiments combined with offshore, long-term deployment of ocean bottom seismographs equipped with absolute pressure sensors to monitor seismicity and vertical seafloor deformation during SSEs. Other critical data sets include active source 2D and $3 \mathrm{D}$ seismic imaging and wide-angle refraction, passive source studies, heat flow surveys, and multibeam seafloor mapping. These auxiliary data are required to help identify drilling targets and to complement borehole monitoring, core, and log data.

Shallow level borehole monitoring (to detect tilt, strain, seismicity, geochemical, and hydraulic transients) along a transect (Fig. 3) is key to addressing questions related to the spatial distribution of slow slip beneath offshore subduction margins, and to reveal the possible relationship between 
SSEs and normal seismicity, as well as to discern changes in fluid flow and geochemistry within the upper plate during the SSE cycle. Depending on the monitoring needs and available resources, instrumentation in the boreholes could range from sophisticated, Circulation Obviation Retrofit Kits (CORK) type installations to simpler Simple Cabled Instrument for Measuring Parameters In Situ (SCIMPI) type devices that do not require standard casing installation. Coring and logging along the same transect are required to characterize in detail the lithology, stratigraphy, structure, fluids, and physical properties within the upper plate above the SSE source regions. Of particular importance is comprehensive coring and log-

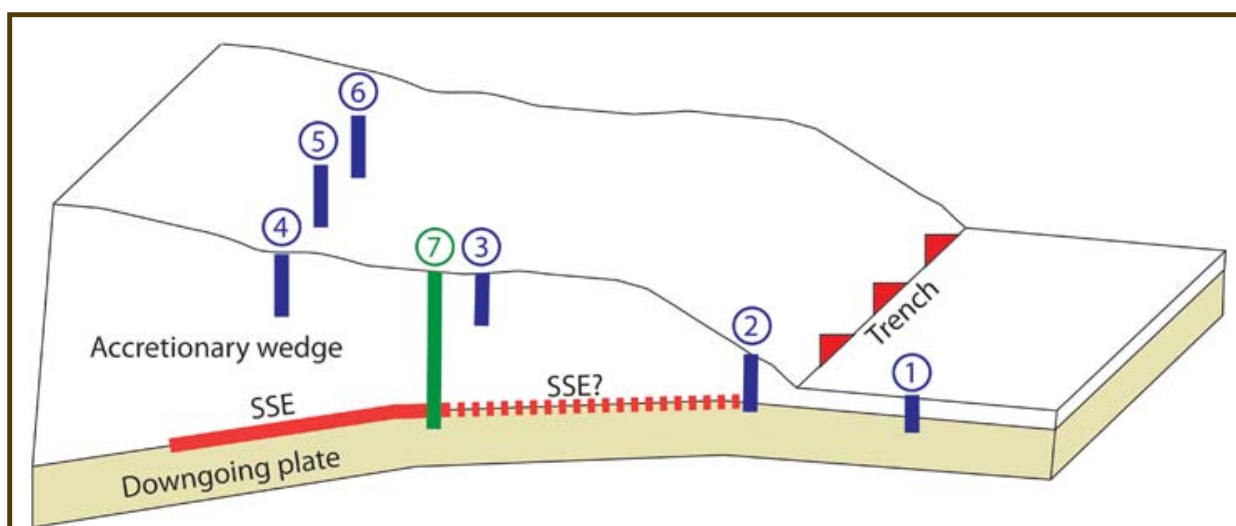

Figure 3. Schematic illustration (not to scale) of a drilling and borehole monitoring scheme which could be applied to address primary SSE questions. See workshop report for further details on the transect design. Note that holes 5 and 6 are positioned off the main transect and are intended for basic monitoring to constrain off-transect variation in SSE behavior. Red patches on the subduction interface show where SSE slip is constrained from onshore instruments. The position of the deep riser hole (\#7) should be constrained by current knowledge of the shallowest part of the interface undergoing SSE. In addition to shallow monitoring and sampling of the upper plate, Site 3 would serve as a pilot hole for the deep riser Site 7 . Site 1 is primarily intended to core and log the input section on the subducting plate. The dashed red line shows a possible trenchward continuation of SSE behavior. Offshore instrumentation (borehole monitoring and seafloor geodesy) will be needed to constrain the updip limit of SSE. ging of the entire input section (e.g., undeformed seafloor sediments on the incoming plate), which will reveal the lithologies likely to be found at depth within the SSE source area. Participants developed an idealized shallow $(<1-2 \mathrm{~km}$ depth) riserless transect design that should achieve the shallow monitoring and coring/logging objectives (Fig. 3). Riser drilling, logging, sampling, and monitoring of the SSE source area would constitute the ultimate, final stage of an SSE drilling program, and would provide the most direct information on the physical conditions (frictional properties, mineralogical composition, fluid pressure conditions, temperature, among others) that lead to and control slow slip event behavior. Targets to intersect SSEs at 5-7 km depth have been identified at some of the shallow SSE locations that were discussed at the workshop. Participants agreed that deep drilling of an SSE source area is within reach and is the ultimate way to solve the mystery of why SSEs occur.

Participants also outlined the characteristics of an "ideal" SSE drilling target. The ideal location must have slow slip occurring somewhat predictably, at depths shallow enough for the source area to be accessible by riser drilling. SSE drilling locations should have a relatively high frequency of SSEs so that multiple cycles can be monitored over a realistic observation period, and the SSEs must be large enough to be measurable and resolvable. Close proximity of the SSE source to the coastline is also advantageous, in order to maximize potential to link with and complement onshore data gathering infrastructure. An SSE target should also have existing $2 \mathrm{D}$ seismic reflection profiles to characterize the structure, interface properties, and geological context for the SSEs.
An interesting discovery during the workshop was the realization by participants that the world's best-documented shallow SSEs in Costa Rica, central Japan, and New Zealand bear some striking similarities to each other. All three locations have relatively cold temperatures on the interface in the SSE source $\left(\sim 100^{\circ} \mathrm{C}-150^{\circ} \mathrm{C}\right)$, similar SSE durations (generally $\sim 2-3$ weeks), comparable equivalent moment magnitudes per event $\left(\mathrm{M}_{\mathrm{w}} \sim 6.5\right)$, and a rough, irregular subducting plate (e.g., subduction of seamounts, ridges, or arc volcanoes). We expect that continued comparisons of these three subduction zones begun at the workshop will lead to new insights into the mechanisms behind shallow SSEs.

Following the workshop, some new and/or revised proposals have been submitted to IODP to conduct ocean drilling related to SSE processes for some of the candidate SSE locations. A detailed workshop report is available to view on the IODP website.

\section{Acknowledgements}

We appreciate generous support for the workshop by IODP-MI, the New Zealand Ministry of Science and Innovation, the Consortium for Ocean Leadership, and NSF/GeoPrisms. We also thank the workshop participants for their contributions to the vibrant, exciting discussions held there, as well as for the excellent oral and poster presentations. Kat Hammond (GNS Science), Joan Gerritse (the Portside Hotel, Gisborne), and Kim Rampling (the Gisborne Conference Center) provided logistical support that was crucial to the success of the workshop. 


\section{References}

Audet, P., Bostock, M.G., Christensen, N.I., and Peacock, S.M., 2009. Seismic evidence for overpressured subducted oceanic crust and megathrust fault sealing. Nature, 457:76-78. doi:10.1038/nature07650

Bell, R.E., Sutherland, R., Barker, D., Henrys, S., Bannister, S., Wallace, L.M., and Beavan, J., 2010. Seismic reflection character of the Hikurangi interface, New Zealand, in the region of repeated Gisborne slow slip events. Geophys. J. Int., 180:34-48. doi:10.1111/j.1365-246X.2009.04401.x

Douglas, A., Beavan, J., Wallace, L., and Townend, J., 2005. Slow slip on the northern Hikurangi subduction interface, New Zealand. Geophys. Res. Lett., 32: L16305. doi:10.1029/ 2005GL023607

Dragert, H., Wang, K., and James, T.S., 2001. A silent slip event on the deeper Cascadia subduction interface. Science, 292:15251528. doi:10.1126/science. 1060152

Ide, S., Beroza, G.C., Shelly, D.R., and Uchide, T., 2007. A scaling law for slow earthquakes. Nature, 447:76-79. doi:10.1038/ nature 05780

Kodaira, S., Iidaka, T., Kato, A., Park, J.-O., Iwasaki, T., and Kaneda, Y., 2004. High pore fluid pressure may cause silent slip in the Nankai Trough. Science, 304:1295-1298. doi:10.1126/ science. 1096535

Liu, Y., and Rice, J.R., 2005. Aseismic slip transients emerge spontaneously in three-dimensional rate and state modeling of subduction earthquake sequences. J. Geophys. Res., 110:B08307. doi:10.1029/2004JB003424

Liu, Y., and Rice, R., 2007. Spontaneous and triggered aseismic deformation transients in a subduction fault model. J. Geophys. Res., 112:B09404. doi:10.1029/2007JB004930

Obara, K., Hirose, H., Yamamizu, F., and Kasahara, K., 2004. Episodic slow slip events accompanied by non-volcanic tremors in southwest Japan subduction zone. Geophys. Res. Lett., 31:L23602. doi:10.1029/2004GL020848

Outerbridge, K.C., Dixon, T.H., Schwartz, S.Y., Walter, J.I., Protti, M., Gonzalez, V., Biggs, J., Thorwart, M., and Rabbel, W., 2010. A tremor and slip event on the Cocos-Caribbean subduction zone as measured by a global positioning system (GPS) and seismic network on the Nicoya Peninsula, Costa Rica. J. Geophys. Res., 115:B10408. doi:10.1029/2009JB006845

Ozawa, S., Suito, H., and Tobita, M., 2007. Occurrence of quasi-periodic slow slip off the east coast of the Boso peninsula, Central Japan. Earth Planets Space, 59:1241-1245.

Peng, Z., and Gomberg, J., 2010. An integrated perspective of the continuum between earthquakes and slow-slip phenomena. Nature Geosci., 3:599-607. doi:10.1038/ngeo940

Sagiya, T., 2004. Interplate coupling in the Kanto district, central Japan, and the Boso Peninsula silent earthquake in May 1996. Pure Appl. Geophys., 161:2327-2342, doi:10.1007/s00024-004-2566-6

Shibazaki, B., and Iio, Y., 2003. On the physical mechanism of silent slip events along the deeper part of the seismogenic zone. Geophys. Res. Lett., 30:GL017047. doi:10.1029/2003GL017047
Song, T.-R.A., Helmberger, D.V., Brudzinski, M.R., Clayton, R.W., Davis, P., Perez-Campos, X., and Singh, S.K., 2009. Subducting slab ultra-slow velocity layer coincident with silent earthquakes in southern Mexico. Science, 324:502-506.

Wallace, L.M., and Beavan, J., 2010. Diverse slow slip behavior at the Hikurangi subduction margin, New Zealand. J. Geophys. Res., 115:B12402. doi:10.1029/2010JB007717

\section{Authors}

Laura M. Wallace (co-chair and local host), GNS Science, P.O. Box 30-368, Lower Hutt, New Zealand; now at University of Texas, Institute for Geophysics, J.J. Pickle Research Campus, 10100 Burnet Road (R2200) Austin, TX 787584445, U.S.A., e-mail: lwallace@ig.utexas.edu

Eli A. Silver (co-chair), Earth and Planetary Sciences, University of California Santa Cruz, 1156 High Street, Santa Cruz, CA 95064-1077, U.S.A.

Nathan Bangs (co-chair), University of Texas, Institute for Geophysics, J.J. Pickle Research Campus, 10100 Burnet Road (R2200) Austin, TX 78758-4445, U.S.A.

Rebecca Bell, Department of Earth Science and Engineering, Imperial College London, South Kensington Campus London SW7 2AZ, London, U.K.

Joshu Mountjoy, National Institute of Water and Atmospheric Research (NIWA), 301 Evans Bay Parade, Hataitai, Wellington 6021, Private Bag 14901, Wellington, New Zealand

Stuart Henrys, GNS Science, 1 Fairway Drive, Avalon 5010, P.O. Box 30-368, Lower Hutt 5040, Lower Hutt, New Zealand Ingo Pecher, GNS Science, 1 Fairway Drive, Avalon 5010, P.O. Box 30-368, Lower Hutt 5040, Lower Hutt, New Zealand; now at University of Auckland, School of Environment, Private Bag 92019, Auckland, New Zealand

\section{Related Web Links}

http://www.iodp.org/doc_download/3480-iodpreportfinal http://drill.gns.cri.nz/DrillNZ/Latest-News/Archive/DrillNZArchive-2011/2011-DrillNZ-Events/Slow-Slip-IODPWorkshop 